\title{
A Visualization Model of Geological Disaster Emergency Scheme Based on Ontology
}

\author{
Luo Xian-gang ${ }^{1}$, Chen Hong-qi ${ }^{2}$, Huang $\mathrm{Lu}^{1,3 *}$, Peng Jing ${ }^{1}$ and Cui $\mathrm{Yi}^{1,3}$ \\ ${ }^{1}$ China University of Geosciences, Faculty of Information Engineering, Wuhan 430074, China; ${ }^{2}$ Chinese Institute of \\ Geo Environment Monitoring Beijing 100081; ${ }^{3}$ Wuhan Zondy T\&S Cyber-Tech CO., LTD, Wuhan 430073, China
}

\begin{abstract}
With the development of information science and technology, how to achieve the digitalization and visualization of geological disaster emergency scheme is an important research subject in the geological disaster emergency command system. This paper designs a visualization model of geological disaster emergency scheme, which was divided into three main steps, including emergency scheme structuring, visualization modeling based on ontology and visualization technology. Based on this, computer technology, GIS(Geographic Information System) technology and network information technology are used to develop the visualization software result of geological disaster emergency scheme. This paper aims to provide a set of scheme for the visualization work of emergency scheme. It contributes to improve the operability of the emergency scheme and provide an intuitionistic intelligent auxiliary means with geological disaster emergency response.
\end{abstract}

Keywords: GIS, emergency scheme, sudden geological disaster, visualization.

\section{INTRODUCTION}

As the basis of geological disaster response, geological disaster emergency scheme is regarded as the standards and guidelines for emergency response [1]. As the emergency command system of geological disasters in China is gradually perfected, a preliminary emergency system of sudden geological disasters has been achieved. However, the informatization scheme only stays at the stage of information management, such as the retrieval, view, addition, deletion, modification of the electronic file, so it is not a good solution for the operability of the scheme [2-5]. Therefore, how to achieve the digitalization and visualization of geological disaster emergency scheme is an important research subject in the geological disaster emergency command system [6].

Guided by the national emergency scheme of geological disaster, this paper analyzes the implementation methods and process of emergency scheme to design a kind of visualization model; in addition, based on this, it develops the visualization software for the emergency response scheme of geological disasters. The traditional scheme has some defects such as boring form, difficulty in query, non-intuitive expression, poor maneuverability, etc [7], and all these defects have been improved. Therefore, it standardizes and visualizes the scheme. It has technically enriched the geological disaster emergency system [1], which could provide an intuitive intelligent assistant decision-making means for abrupt geological disaster emergency response.

\footnotetext{
*Address correspondence to this author at the Optics Valley Software Park A10\#, No.1, Guanshan Avenue, East Lake High-Tech Development Zone, Wuhan, Hubei, P.R. China, Postcard: 430073; Tel: 13554685466;

E-mail: huanglu213@163.com
}

\section{VISUAL DECISION PROCESS OF EMERGENCY SCHEME}

The process flows of the emergency scheme includes reporting the disaster, launching the emergency scheme, emergency response, emergency guarantee and other major implementation processes. When sudden geological disasters occur, how to quickly extract the elements of schemes and form specific and feasible emergency scheme is the key to ensuring efficient emergency response [1]. The flow chart of emergency scheme decision-making is shown in Fig. (1).

Among them, the rating scale of the geological disasters and hazards is shown in Table $\mathbf{1 .}$

\section{VISUALIZATION MODEL OF THE SCHEME}

The visualization model of the emergency scheme of geological disasters is based on the national emergency scheme of geological disasters, which is realized by turn from the aspects of the structuralization of the emergency scheme, ontology-based digital modeling of the emergency scheme, and the visualization of the emergency scheme. The visualization structure model of its emergency scheme is shown in Fig. (2).

\subsection{Structuralization of the Emergency Scheme}

The structuralization of the emergency scheme is the digital processing of the text scheme of the national emergency scheme for geological disasters, which will form an emergency scheme library. All the information in the library should be expressed in a structured way [2], which is an important prerequisite to achieve the visualization of the emergency scheme [8]. 


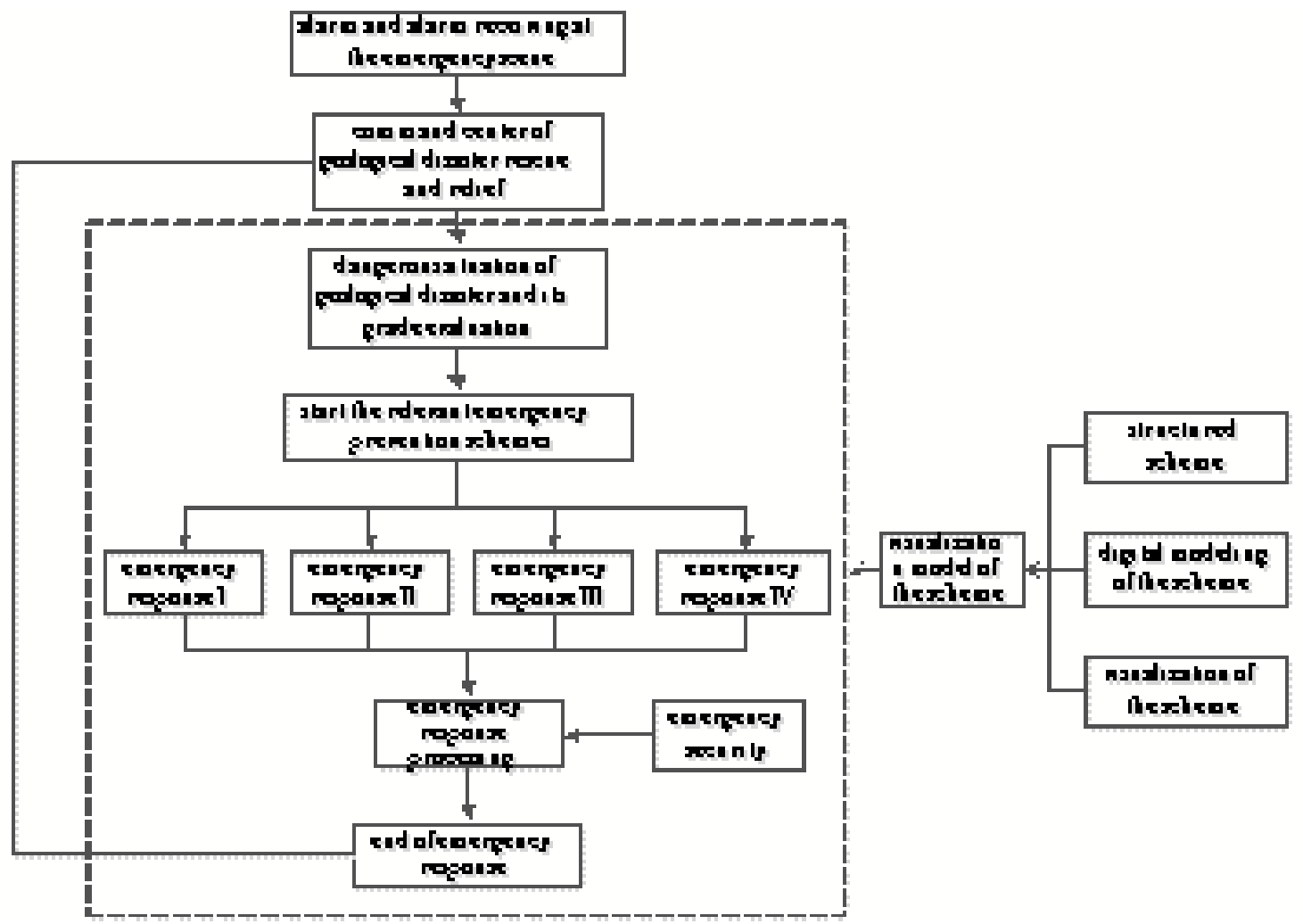

Fig. (1). The flow chart of the decision-making of the emergency scheme.

Table 1. Rating scale of the geological disaster degree (disasters and hazards).

\begin{tabular}{|c|c|c|c|c|c|c|}
\hline \multicolumn{3}{|c|}{$\begin{array}{c}\text { Indicator Level } \\
\text { Type and Unit of Measurement }\end{array}$} & \multirow{2}{*}{$\begin{array}{c}\begin{array}{c}\text { Super Large-Scale } \\
\text { (Disaster at Level I) }\end{array} \\
\quad \geq 30\end{array}$} & \multirow{2}{*}{$\begin{array}{c}\text { Large-Scale } \\
\text { (Disaster at Level II) } \\
30 \sim 10 \text { (including 10) }\end{array}$} & \multirow{2}{*}{$\begin{array}{c}\begin{array}{c}\text { Comparatively Large-scale } \\
\text { (Disaster at Level III) }\end{array} \\
10 \sim 3 \text { (including 3) }\end{array}$} & \multirow{2}{*}{$\begin{array}{c}\text { Common } \\
\text { (Disaster at Level IV) }\end{array}$} \\
\hline 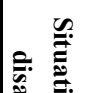 & dead or missing & $\begin{array}{l}\text { number of } \\
\text { people }\end{array}$ & & & & \\
\hline 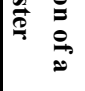 & $\begin{array}{l}\text { direct economic } \\
\text { losses }\end{array}$ & ten thousand & $\geq 1000$ & $\begin{array}{l}1000 \sim 500 \text { (including } \\
500 \text { ) }\end{array}$ & 500 100(including 100) & $<100$ \\
\hline 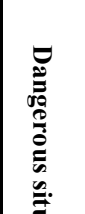 & $\begin{array}{l}\text { people should } \\
\text { relocate due to } \\
\text { the threat of } \\
\text { geological disas- } \\
\text { ters }\end{array}$ & $\begin{array}{l}\text { number of } \\
\text { people }\end{array}$ & $\geq 1000$ & $\begin{array}{l}500 \sim 1000 \text { (including } \\
1000 \text { ) }\end{array}$ & $500 \sim 100$ (including 100) & $<100$ \\
\hline . & $\begin{array}{l}\text { potential eco- } \\
\text { nomic losses }\end{array}$ & ten thousand & $\geq 10000$ & $\begin{array}{l}\text { 10000 5000(including } \\
5000 \text { ) }\end{array}$ & $5000 \sim 500$ (including 500) & $<500$ \\
\hline 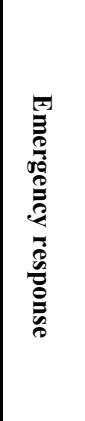 & & & $\begin{array}{l}\text { It is led by the Provin- } \\
\text { cial People's Govern- } \\
\text { ment, combined with } \\
\text { the coordination and } \\
\text { command from the } \\
\text { headquarters of Provin- } \\
\text { cial Emergency Preven- } \\
\text { tion and Control of } \\
\text { Geological Disasters. }\end{array}$ & $\begin{array}{l}\text { It is led by the Provin- } \\
\text { cial People's Govern- } \\
\text { ment, combined with } \\
\text { the coordination and } \\
\text { command from the } \\
\text { headquarters of Provin- } \\
\text { cial Emergency Preven- } \\
\text { tion and Control of } \\
\text { Geological Disasters. }\end{array}$ & $\begin{array}{l}\text { It is led by the Municipal } \\
\text { People's Government, com- } \\
\text { bined with the coordination } \\
\text { and command from the } \\
\text { headquarters of Municipal } \\
\text { Emergency Prevention and } \\
\text { Control of Geological Disas- } \\
\text { ters. }\end{array}$ & $\begin{array}{l}\text { It is led by the County } \\
\text { People's Government, } \\
\text { combined with the } \\
\text { coordination and } \\
\text { command from the } \\
\text { headquarters of } \\
\text { County Emergency } \\
\text { Prevention and Con- } \\
\text { trol of Geological } \\
\text { Disasters. }\end{array}$ \\
\hline
\end{tabular}




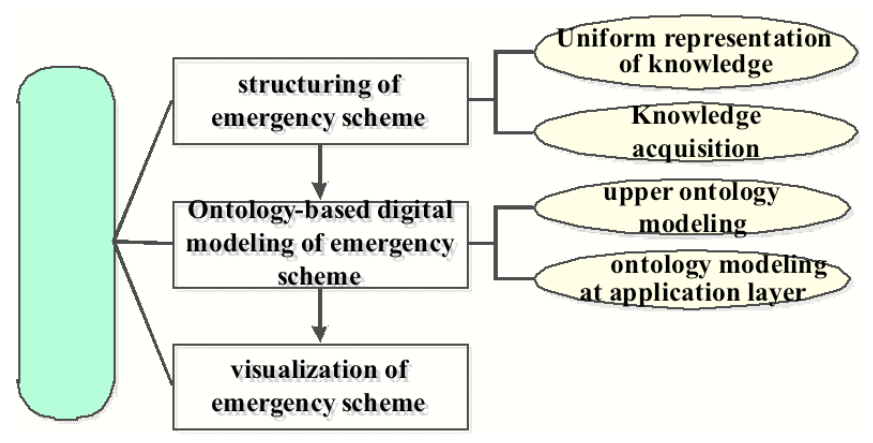

Fig. (2). The visualization structure model of the emergency scheme.

It has two key points:

\section{(1) Unified representation of knowledge}

It means to carry out structural decomposition on the various elements of text emergency schemes. Through the extraction of entries and text parsing, the elements of the scheme are extracted to form a targeted and feasible emergency scheme.

The information and knowledge described in the national emergency scheme for sudden geological disasters are expressed in a structured and unified way, including rating of disasters and haphazard, emergency response, emergency guarantee and many other aspects. The structural elements of emergency schemes need to adopt a unified way to describe and must follow certain rules to form a standardized structure [2], so as to ensure that the data of emergency schemes can be stored in a unified, and efficient way.

\section{(2) Knowledge acquisition}

Conduct an in-depth analysis and study of the text scheme in the national emergency scheme for sudden geological disasters to ascertain the knowledge that needs to be represented in the emergency schemes as well as the acquisition ways of them and to carry out knowledge representation and knowledge acquisition. The database technology is also applied to achieve a unified management of the structuralization of emergency schemes in the computer and their structured storage.

\subsection{Digital Modeling of Ontology-Based Emergency Scheme}

ABC (Antecedent-Behavior-Consequences) ontology model is to describe the creation, change and transfer of the object as time goes on, and then use some concept such as Event, Situation, Action, Agent concepts and the conceptual relations to express the content of the event and the changing process over time [9]. Ontology model has the two-tier structure, the upper ontology and ontology at the application layer.

\subsubsection{Upper Ontology Modeling}

Adopt the extended $\mathrm{ABC}$ ontology to conduct modeling and establish the conceptual models for the organizational structure, emergency response, action process related to this study area, and call the constrained relationship. The structure of its extended ABC ontology model is as shown in Fig. (3).

(1) Emergency refers to the sudden incident in a region which requires activating emergency schemes. This concept, as an extended subclass of the Event, has an attribute Level: level I- super large-scale, level II - large-scale, level IIImedium-scale, level IV-small-scale geological disasters.

(2) Emergency Response refers to the emergency measures of geological disasters at different levels. As an extended subclass of Temporality, it is triggered by the Emergence of sudden geological disasters.

(3) Expert and Personnel are the organization and staff responsible for the emergency command, and it is an extended subclass of action subject Agent.

(4) Resource is used for emergency security including response team, funds, materials, equipment, etc.

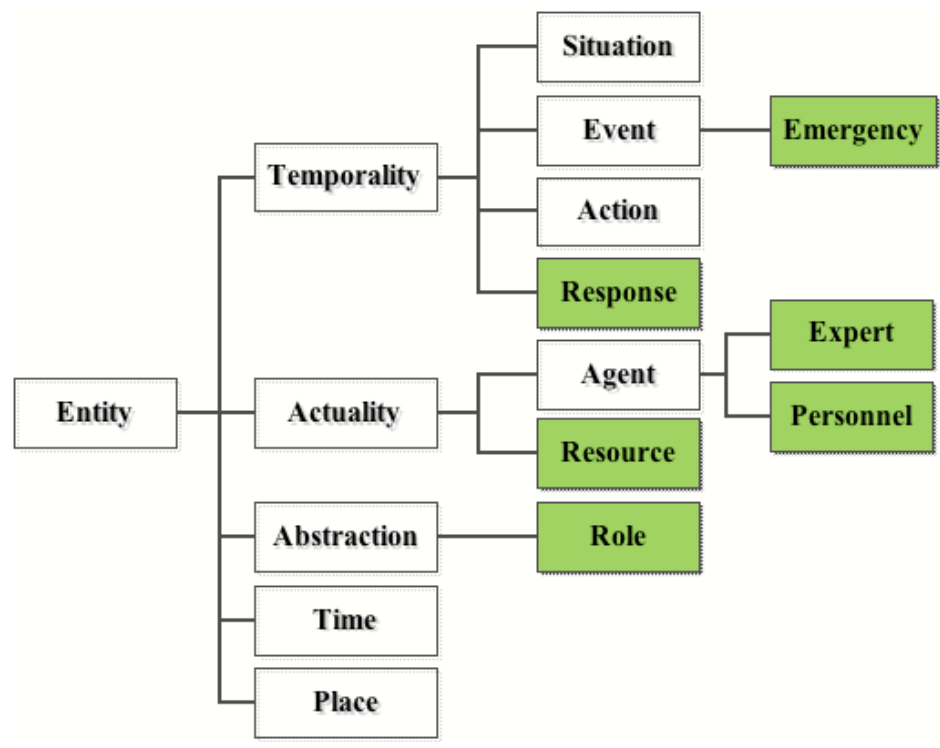

Fig. (3). Structure of extended ABC ontology model class. 


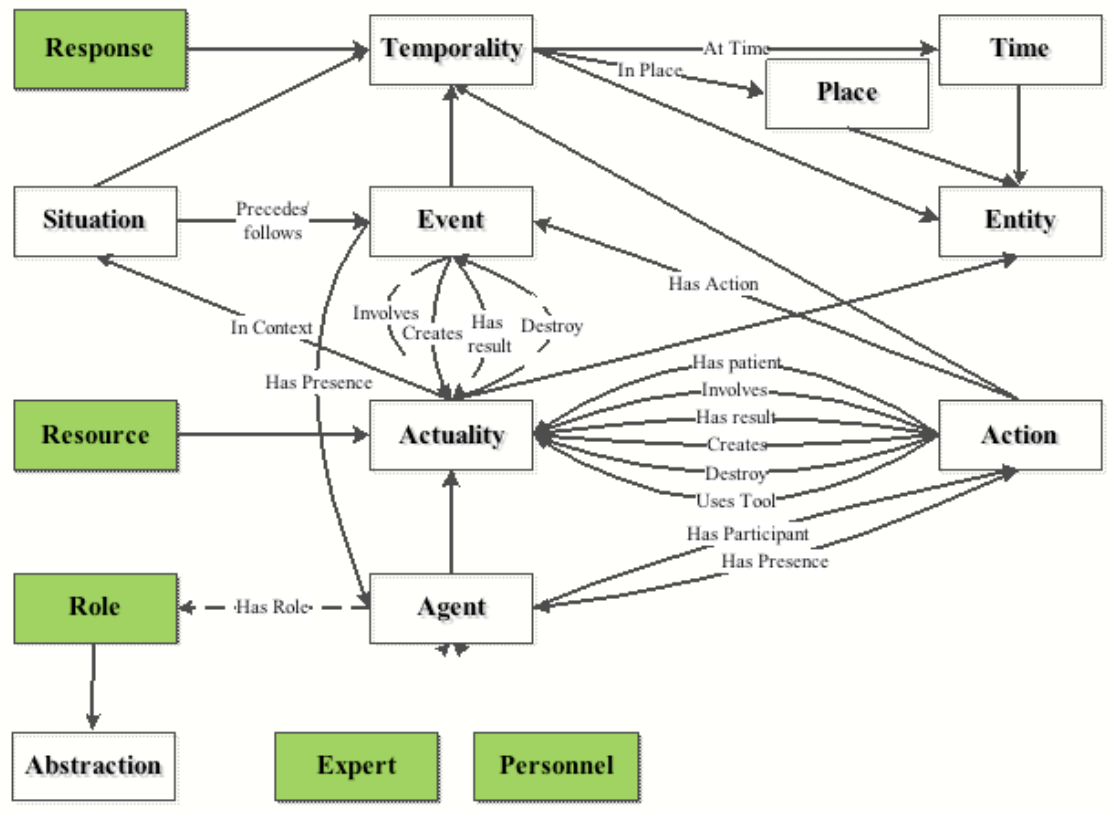

Fig. (4). Structure of extended ABC ontology model class.

(5) Role refers to the function of action subject Agent, and it is an extended subclass of Abstraction.

The extended $\mathrm{ABC}$ ontology model utilizes the ontology languages to describe the basic knowledge involved by geological disaster emergency schemes as much as possible. The description for the semantic relations between emergency process-related concepts is as shown in Fig. (4).

\subsubsection{Ontology Modeling at Application Layer}

The extended $\mathrm{ABC}$ is regarded as the upper ontology to build the ontology modeling at application layer of the emergency scheme. EC_ Domain Ontology can be defined as a quintuple:

\section{EC_DomainOntology $=<$ EC_Concepts,}

EC_Relations, EC_Functions, EC_Axioms, EC_Instances>

EC_Concepts, EC_Relations,

EC_Functions, EC_Axioms, EC_Instances

respectively denotes a collection of concepts, a collection of binary relations between concepts, a collection of conditional rules, a collection of valid axiom, examples of concepts [9].

\section{(1) EC_Concepts}

EC_Concepts $=\{C\}$ represents the collection of concepts in the emergency schemes of sudden geological disasters, mainly including Emergency Information, Emergency geological disasters, Behaviour Subject, Behaviour Object, Emergency Event Developmental Process, Emergency Response, Organizational Framework, Emergency Resource, etc.

\section{(2) EC_Relations}

EC_Relations $=\left\{\mathrm{R}(\mathrm{c} 1, \mathrm{c} 2) \mid \mathrm{c} 1, \mathrm{c} 2 \in \mathrm{EC} \_\right.$Concepts $\}$refers to the collection of binary relations between concepts of the emergency scheme, mainly including compose, use, implements, has Role, follows, etc.

(3) EC_Functions

EC_Functions $=\{\mathrm{F}$ :

$\mathrm{S} 1 \times \mathrm{S} 2 \times \ldots \times \mathrm{Sn} \times \mathrm{T} \rightarrow \mathrm{S}\} \mid \mathrm{S} 1, \mathrm{~S} 2, \ldots, \mathrm{Sn}, \mathrm{S} \in$

EC Concepts $U E C$ Relations, T $\in$ EC Concepts $\}$ means the collection of transfer rules between situations, where $\mathrm{Si}$ represents the place of the event, $\mathrm{T}$ is the current transfer condition.

(4) EC_Axioms

EC_Axioms $=\{\mathrm{A}: \mathrm{S} 1 \times \mathrm{S} 2 \times \ldots \times \mathrm{Sn} \rightarrow \mathrm{S} \mid$

$\mathrm{S} 1, \mathrm{~S} 2, \ldots, \mathrm{Sn} \in \mathrm{EC}$ Concepts $\cup E C$ Relations $\cup E C$ Functions, $\mathrm{S} \in \mathrm{EC}$ CConcepts $\cup E C$ Relations $\}$, condition $\mathrm{T}$ does not exist in EC_Axioms transfer rules, meaning it is true in any context.

\section{(5) EC Instances}

EC_Instances $=\{$ Instance $\mid$ instance $\in$ EC_Concepts $\cup E C$ _ Relations $\}$, representing the instantiation of concept and relation in the emergency scheme.

\subsection{Visualization of Emergency Schemes}

Based on the above structure and digitization, the visualization of emergency scheme is to adopt the current advanced data visualization technology, geographic information system (GIS) technology to build a visualization system, namely, conducting visualization for knowledge, so that emergency schemes can be visually expressed through a graphic.

Associate the situation of the areas greatly suffering from geological hazards, emergency schemes and specific information in GIS layers to display the geological hazard information and measures in emergency schemes to users in a complete way. Combined with GIS maps, integrate the spatial and temporal information through the browser to display 
the disposal process of the emergency schemes in the form of a flowchart [10].

\section{RESULTS ACHIEVEMENT}

According to the decision-making process of its visualization process and utilizes its visualization model, combined with the database technology, geographic information technologies (GIS) and network information technology to achieve the visualization system.

\subsection{Functions Achievement}

According to the requirements of Emergency Scheme of National Sudden Geological Disaster, the system is designed as several functional modules, including disaster reporting, disaster grade determination, disaster emergency security, disaster emergency response, disaster assessment, system management, etc., and there is a logic relation between these modules. Fig. (5). is the core function block diagram of the emergency scheme's visualization system.

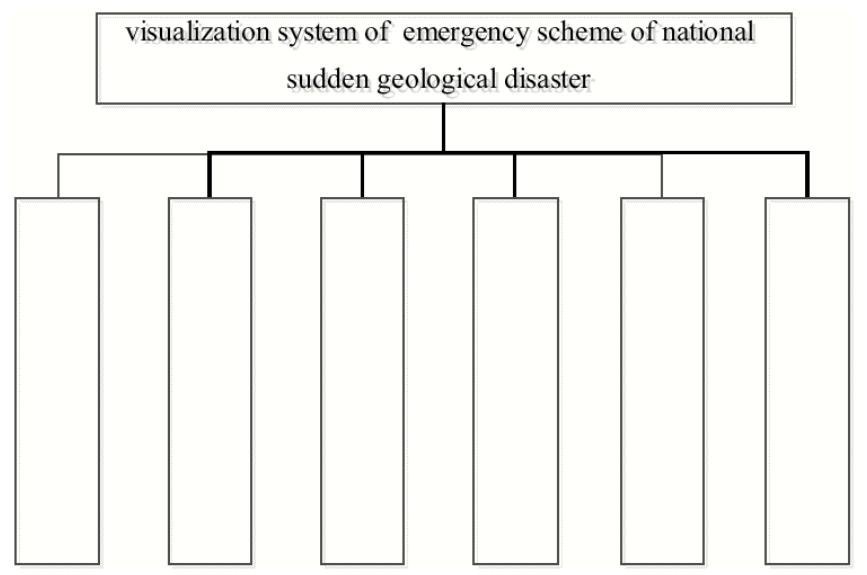

Fig. (5). The function block diagram of visualization software of emergency scheme of national sudden geological disaster.

\section{(1) Disaster reporting}

Monitor working staff's reporting of the form of emergency scheme for geological disasters. Make sure they fill the disaster and haphazard information of geological disasters based on the content of the form.

\section{(2) Disaster level evaluation}

System can automatically determine the level of disasters and haphazard of geological disasters according to casualties, economic losses and thereat level in the form, and mark the location of the specific disaster and haphazard point in the map. Tap the point and we can see the disaster and haphazard information of the point.

\section{(3) Disaster emergency security}

Configure and equip emergency response teams, funds, materials, and equipment to set up an emergency expert and working groups according to the disaster level of geological disasters.

(4) Disaster emergency response

Emergency expert and working groups commence sudden geological disaster emergency work, and delimit geo- logical hazard zone, establish warning signs, and select evacuation routes combined with the specific circumstances of disasters and haphazard.

\section{(5) Disaster assessment}

Assess the disaster after the end of the entire emergency response to geological disasters and improve the various information of describing the disaster, such as causes, impact, work progress, analysis of the development law of geological disasters and introspection of emergency work.

\section{(6) System Management}

Manage the basic information of users, including changing passwords and log information, and other basic operations, as well as reminder function of a number of important issues and events.

\subsection{System Operation and Results}

The visualization system of emergency scheme makes full use of its structuralization and digitization based on ontology and visualization representation techniques and applies SQL Server database and GIS to build an all-in-one information system. The operating results of the visualization system of national emergency schemes for sudden geological disasters are shown in.

\section{CONCLUSION}

The visualization of the emergency scheme for geological disasters is a hot topic of the application of the emergency command and decision-making in the current geological disasters, but this area is still in its infancy. This paper has designed a set of visualized decision-making processes of emergency schemes for geological disasters and visual models of schemes and has accomplished the expected results of the visualization system of emergency schemes for geological disasters, which has carried out analysis and reflection at all levels from the theory, methods and applications. However, with the strengthening of practical applications, there are some issues to be resolved, such as how to use intelligent analysis means to achieve intelligent emergency schemes and achieve rapid analysis and optimization assessment of emergency programs [11]. In the future course of the study, it still requires further in-depth analysis and improvement.

\section{CONFLICT OF INTEREST}

The authors confirm that this article content has no conflict of interest.

\section{ACKNOWLEDGEMENTS}

The paper is funded by Special Project of Ministry of Land and Resources for Public Industry Research (201211055) and the Central Universities (CUGL130259), the views expressed are the authors' alone.

\section{REFERENCES}

[1] Q. Tong, J. Y. Zhang, C. Chen, "Research on the GIS -based visualization of contingency schemes", Computer Engineering and Applications, vol. 47, no. 20, pp. 4-8, 2011

[2] J. Y. Shen, D. X. Du, H. W. Xie, "Research on the digitization 
system of emergency schemes and its implementation", Information Development \& Economy, vol. 18, no. 36, pp. 105-108, 2008.

[3] B. Shi, "Research on Some Issues in Emergency Plan Management", Hefei: University of Science and Technology of China, 2012.

[4] X. D. Zhang, D. Liu, K. Yu, "Open XML-based approach for digitization of emergency plans", Computer Engineering and Design, vol. 33, no. 6, pp. 2246-2250, 2012.

[5] F. Zhang, Y. B. Han, "Emergency response process construction based on digital plans", Computer Integrated Manufacturing Systems, vol. 19, no. 8,pp. 1802-1809,2013.

[6] L. Huang, X. G. Luo, Y. X. Huang, "Design and realization of emergency command information system for geological disaster", Scientific and Technological Manngement of Land and Resources, vol. 29, no. 6, pp. 141-145, 2012.

[7] K. Li, "Design and Implementation of Electronic Sand Table-based
Fire Scheme Visualization System", Tianjin: Tianjin University, 2011.

[8] Z.B. Wang, "Digital Research and Application of Contingency Schemes of Tianjin Binhai Mass Transit", Tianjin: Tianjin University, 2008.

[9] L. Zhang, "Digitization Method and Its Application of the Ontology-based Contingency Schemes for Urban Rail", Beijing: Beijing Jiaotong University, 2012.

[10] X. Li, W. Wang, Y. Ben, "Intelligent Visualization Platform of Emergency Schemes for Campus", Computer Applications, vol. 26, no. 9, pp. $3369-3387,2009$.

[11] C. Zhang, Y. Q. Pei, H. Qiu, "Development status and trends of digitization technology of contingency schemes at home and abroad", China Safety Science and Technology, vol. 6, no. 5, pp. 154-158, 2010.

Received: September 22, 2014

Revised: November 30, 2014

Accepted: December 02, 2014

(C) Xian-gang et al.; Licensee Bentham Open.

This is an open access article licensed under the terms of the Creative Commons Attribution Non-Commercial License (http://creativecommons.org/licenses/by-nc/3.0/) which permits unrestricted, non-commercial use, distribution and reproduction in any medium, provided the work is properly cited. 